\title{
Warning Signs and Symptoms of Oral Cancer and its Differential Diagnosis
}

\author{
Kavitha Muthu ${ }^{* 1}$, Vedam Vaishnavi ${ }^{2}$, Ganapathy Sivadas ${ }^{3}$ \\ 'Department of Oral Pathology, RVS Dental College and Hospital, Coimbatore, Tamil Nadu, INDIA. \\ 2Department of Oral Pathology, Faculty of Dentistry, Asian Institute of Medicine, Science and Technology (AIMST) University, Kedah, MALAYSIA. \\ ${ }^{3}$ Department of Pedodontics and Preventive Dentistry, Faculty of Dentistry, Asian Institute of Medicine, Science and Technology (AIMST) University, Kedah, MALAYSIA.
}

\begin{abstract}
Oral Cancer (Oral Squamous Cell Carcinoma; OSCC) contributes to one of the important causes of mortality in human beings. These impending malignancies however may present clinically with warning signs and symptoms which is often neglected due to the lack of awareness in the population. Though there are developments in diagnosing early stage of oral cancer,the detection rate is continued to be minimal. Research proved a strong association between early diagnosis and better prognosis in these malignancies. Hence, knowledge regarding these warning indicators will certainly facilitate the clinicians to discover early cancer and provide an overall benefit pertaining to treatment in these patients. This review aims to highlight the early signs and symptoms of OSCC and their significance in improved prognosis of the patients. A Medline-PubMed search was conducted of the literature over the past years using the keywords: "oral squamous cell carcinoma", "warning signs," "Early symptom", "clinical presentation," "white lesion," "ulcer," "erythroplakia", and "abnormal growth". A total of 58 articles were reviewed, of which 11 were literature reviews, 15 were original studies and 32 were case reports. Appropriate Asssesment
\end{abstract}

and analysis were performed to identify prompt warning signs and symptoms of OSCC. The key findings of all the early presentation were Eloborated with its clinical significance. In addition,this paper also helps to identify particular type of oral malignancies with their common clinical presentation reaching its emphasis based on the warning signs and symptoms. The importance of re-evaluation and biopsy to diagnose/eliminate malignant lesion in doubtful clinical situation is also highlighted.

Key words: Oral cancer, Warning signs, Symptoms, Persistent ulcer, White/red patch.

\section{Correspondence}

Dr.Kavitha Muthu, MDS (Oral Pathology), Reader, Department of Oral Pathology, RVS Dental College and Hospital, Coimbatore, Tamil Nadu, INDIA. Email: kavidentist@yahoo.co.in

DOI: 10.5530/jyp.2018.10.32

\section{INTRODUCTION}

Oral and maxillofacial cancer (malignancy) contribute to one of the primary reasons of mortality worldwide. According to histological data, oral squamous cell carcinoma accounts for majority of all oral cancer. Dentists add to the crucial group of health care professionals in diagnosing oral cancers by observing essential warning signs and symptoms on examination of the oral cavity and confirming with suitable diagnostic aids. Thus, pertaining to the oral region, a "sign" refers to an objective evidence of a oral condition detected by a dentists during the examination of the oral cavity while a "symptom" refers to a subjective evidence of disease or a patient's oral condition. Few signs may go unnoticed by the patient although they remain meaningful and significant to the healthcare provider in assisting the diagnosis of medical condition(s) responsible for the patient's symptoms. Among all the dental signs and symptoms detected on regular history and examination of the patients, the warning sign points to the intimation, threat, or sign of an impending danger of the underlying disease. Usually, at the molecular level, the cells undergo multistep process which includes initiation, proliferation and progression to become cancer cells during the pathogenesis of oral cancer. The clinical features also depend upon the etiopathological behavior of the individual tumors.

In this article, warning signs and symptoms of oral cancer (Table 1,2) from the review of the available literature has been highlighted which might be first signal of undiscovered malignancies. These signs and symptoms adds clue to the clinicians that aid in early diagnosis, timely evaluation and improved prognosis for the patients from an oncological perception. The other associated oral malignancies with the warning sign and symptoms are also highlighted (Table 3 ) which would be helpful for differential diagnosis in essential clinical situation.

\section{WARNING SIGNS AND SYMPTOMS OF ORAL CANCER AND ASSOCIATED MAXILLOFACIAL MALIGNANCIES}

\section{Non Healing Ulcer [ Figure 1]}

Ulcerations in the mouth may exhibit from a simple to highly complex variations suggestive of oral malignancy. In other words, patients present with this chief complaint of "ulceration" depicting to the epithelium and connective tissue damage with the existence of an obvious central crater caused by oedema or proliferation in the surrounding tissue. ${ }^{1}$ Health care professional must clearly grasp the distinction between malignant/ premalignant lesions from the group of reactive lesions persisting for more than two weeks following the removal of etiological factors. These lesions become more suspicious when it increases in its intensity and turns non responsive to the ongoing treatment. Therefore, appropriate diagnostic procedures (i.e., gold standard biopsy in addition to other non-invasive chairside procedures of the lesion) are essential diagnostic

This is an open access article distributed under the terms of the Creative Commons Attribution-NonCommercial-ShareAlike 4.0 License, which allows others to remix, tweak, and build upon the work non-commercially, as long as the author is credited and the new creations are licensed under the identical terms. 
aids in the evaluation of any lesion that does not respond to usual therapy in 7 to 14 days. ${ }^{2}$ Common oral and maxillofacial malignancies presented as persistent non healing oral ulcers are briefed in the following discussion.

- Squamous cell carcinoma - Characteristically, squamous cell carcinoma appears as red or white, painless, indurated, non-healing ulcer with elevated and ill-defined margins. Most of the oral carcinomas may present with history of long standing non-healing ulcero-proliferative lesion with a rolled or indurated border. Common primary tumor sites of the oral cavity as reviewed in literature is attributed to buccal mucosa, tongue, lower alveolus, gingiva, floor of the mouth and palate. ${ }^{3,4}$

- Salivary gland tumor - Salivary gland malignancies (muco-epidermoid carcinoma and adenoid cystic carcinomas) occur predominantly in the palate, cheek and gingival region of the jaws as a chronic ulcer. $^{5,6}$

- Lymphomas- Lymphomas may present as chronic ulcer covered with necrotic slough in the palatal region of the jaw in specific tumors of palate and paranasal sinus. ${ }^{7,8}$

- Leukemias- Unlike, lymphatic tumours, leukemic tumours occur commonly in the gingival region of the mouth mimicking the clinical picture as lymphomas. ${ }^{9,10}$

- Basal cell carcinoma ${ }^{11}$ and Metastatic tumors ${ }^{12,13}$ may also present as ulcer

\section{White Patch With Firm Consistency [Figure 2]}

Lesions appear "white" due to the reflection of the spectrum of light by abnormal keratin and constant bathing of the hyperkeratotic tissue in saliva, analogous to the appearance of palms and soles when immersed in water for long periods. ${ }^{14}$ These lesions predominantly are seen in the tongue, floor of the mouth and buccal mucosa. ${ }^{2}$ Non-scarpable firm white lesions could be sub categorized as heterogenous or homogenous groups. White papillary lesions of heterogenous variant measuring more

\section{Table 1: Potential warning signs/symptoms of the oral cancer.}

- Non healing ulcer with or without induration / nonhealing socket

- White patch with firm consistency

- $\quad$ Red lesion or lesion with erythematous appearance (Erythroplasia)

- Abnormal lump in the mouth with increase in size

- Exophytic/ulceroproliferative growth

- Mass or lump in the neck and neigbouring regions (Lymph node enlargement)

- Mobility/displacement/ non vital teeth/peri implantitis

- Tooth pain and referral pain

- Bleeding from the mouth (hemorrhage) than $1 \mathrm{~cm}$ usually denotes Verrucous carcinomas. Malignancies associated with these white patch includes Squamous cell carcinoma and Its variants. ${ }^{15,16}$

\section{Red Patch (Erythroplasia) or Mixed White and Red Patch/ Lesions [Figure 3]}

Red patches differ from early flat lesions to raised blotches or lumps complicating the clinical scenario and prognosis of the patient. These lesions appear true, velvety, red homogeneous to granular, velvety hetereogeneous lesions in nature. They occur most commonly on the lateral surface of the tongue and floor of the mouth indicating the sites of poor prognosis. ${ }^{17}$ Areas of redness and inflammation as changes of mucosal abnormality, at high-risk sites persisting for more than 14 days without any obvious etiology or resolution should be biopsied and treated promptly. Unlike leukoplakia or other mixed lesions, persistent asymptomatic or symptomatic erythroplastic lesions at any site should be considered to be invasive carcinoma or at the very least carcinoma in situ. These lesions at high-risk sites also indicate the earliest and predominant sign of oral Squamous cell carcinoma. Common oral malignancies presented as red lesions includes Invasive squamous cell carcinomas, ${ }^{18}$ Kaposi sarcoma ${ }^{19}$ and Basal cell carcinoma. ${ }^{11}$

\section{Abnormal Lump in the Mouth with Increase in Size [Figure 4]}

Many of the oral malignancies present as an abnormal lump which usually increase progressively in size. The surface would be smooth, erythematous, or ulcerated due to secondary trauma. The site occurrence would include either soft tissues or jaw bones. Common malignancy with this sign includes Squamous cell carcinoma, ${ }^{4}$ Basal cell carcinoma, ${ }^{11}$ Salivary gland malignancies, ${ }^{20}$ Sarcoma, ${ }^{21}$ Melanoma, ${ }^{22}$ Lymphoma,${ }^{23}$ Intra osseous malignancies of maxilla and mandible ${ }^{24}$ and Metastatic malignancies. ${ }^{25}$

\section{Exophytic/ Ulceroproliferative Growth [Figure 5]}

Exophytic lesions depicts an uncontrolled pathological growth of the oral mucosal surface with erythematous or mixed appearance. They usually occur in the buccal mucosa, alveolar ridge of maxilla and mandible, gingiva, floor of the mouth and the palate. Common malignant lesions with exophytic/ulceroproliferative nature of growth includes, Squmous cell carcinoma and its variants. ${ }^{15,26}$

Verrucous carcinoma account for 4.5-9\% of oral squamous-cell carcininomas which typically present as a slowly enlarging, gray or white, warty, exophytic growth on the buccal mucosa or gingiva of elderly men at the time of examination. ${ }^{16}$ Other tumors which may appear as exophytic include Sarcomas, ${ }^{21}$ Salivary gland neoplasms, ${ }^{20}$ Sialadenoma papilliferum with malignant changes,${ }^{27}$ Metastatic tumors ${ }^{15}$ and Multiple myeloma. ${ }^{28}$

Table 2: Warning Signs/symptoms according to the clinical presentation.

\begin{tabular}{|c|c|c|}
\hline Soft tissue associated & Hard tissue associated & Generalised \\
\hline $\begin{array}{l}\text { Non healing ulcer with or without } \\
\text { induration / nonhealing socket } \\
\text { White patch with firm consistency } \\
\text { Red patch (Erythroplasia) or mixed } \\
\text { white and red patch/ lesions. } \\
\text { Abnormal lump in the mouth with } \\
\text { increase in size. } \\
\text { - Exophytic/ulceroproliferative growth } \\
\text { Mass or lump in the neck (Lymph node } \\
\text { enlargement) } \\
\text { Bleeding from the mouth (hemorrhage) }\end{array}$ & $\begin{array}{ll}\text { - } & \text { Tooth pain } \\
\text { - } & \text { Mobility /displacement /non vital teeth } \\
\text { - } & \text { Peri implantitis }\end{array}$ & - $\quad$ Referral pain. \\
\hline
\end{tabular}




\section{Table 3: Warning signs and symptoms and their commonly associated oral malignancies.}

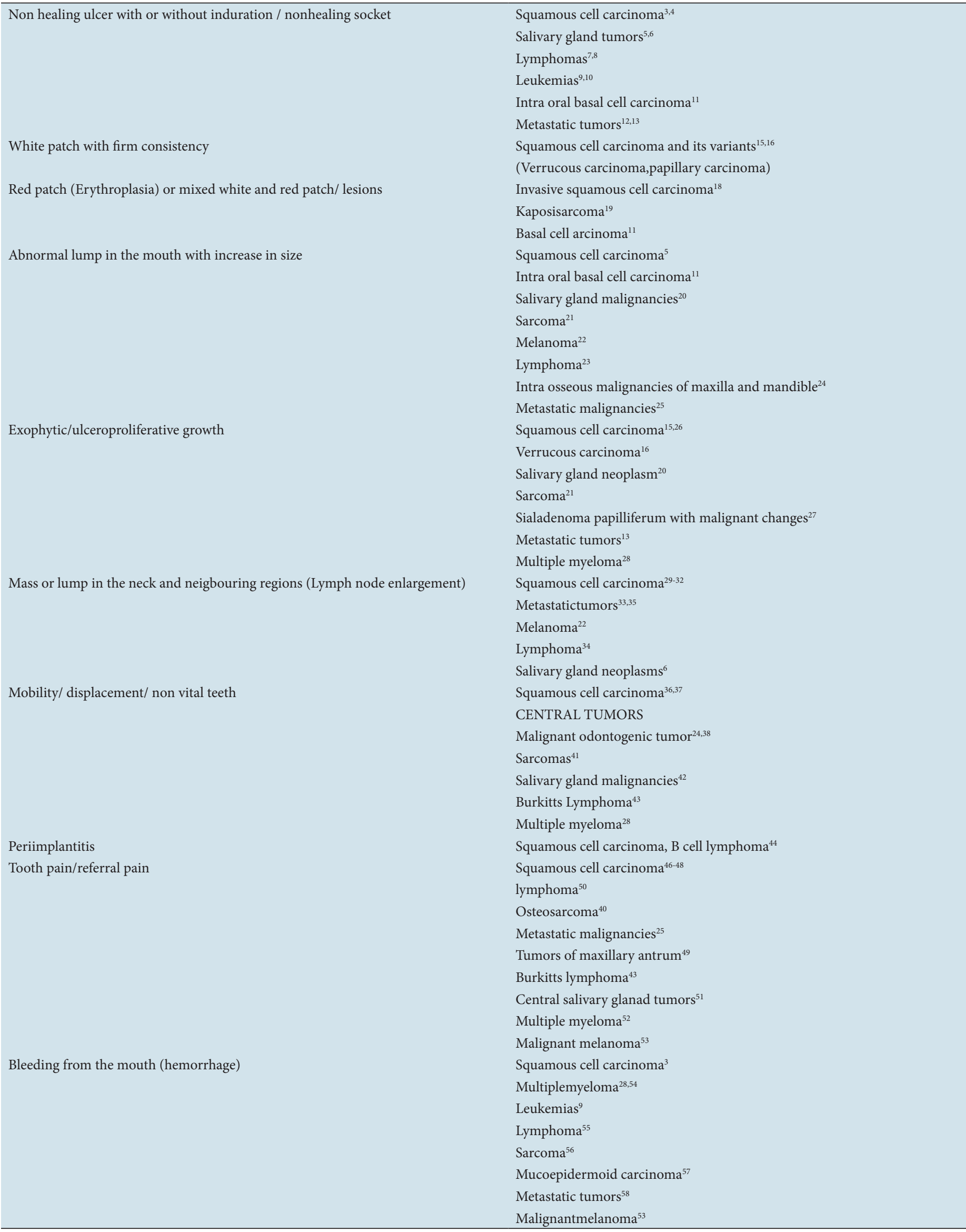




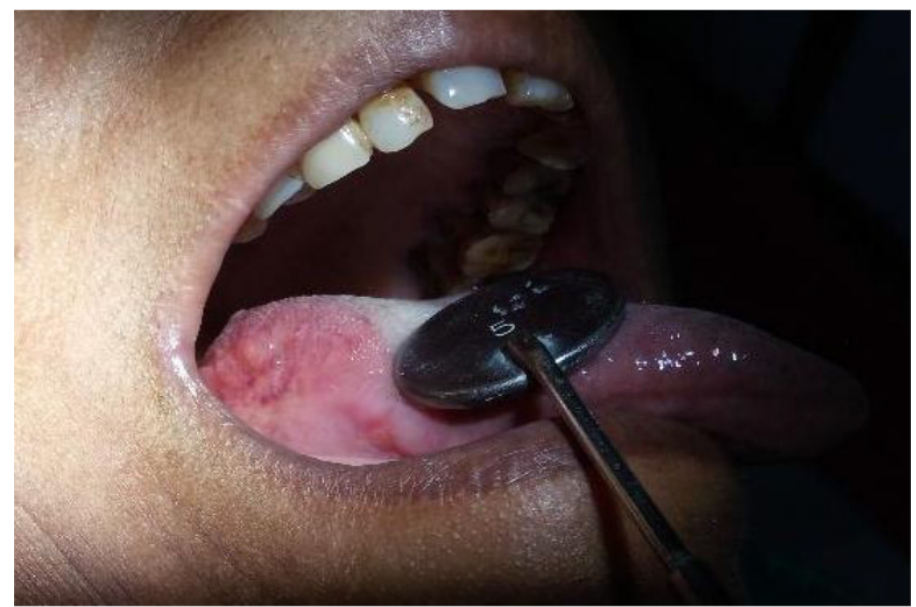

Figure 1: Non-healing ulcer.

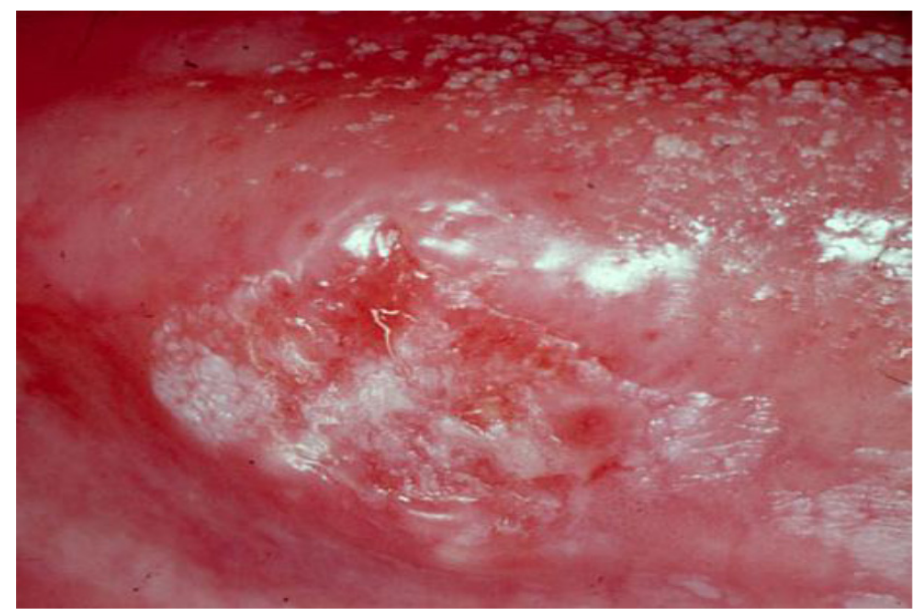

Figure 2: Firm white patch.

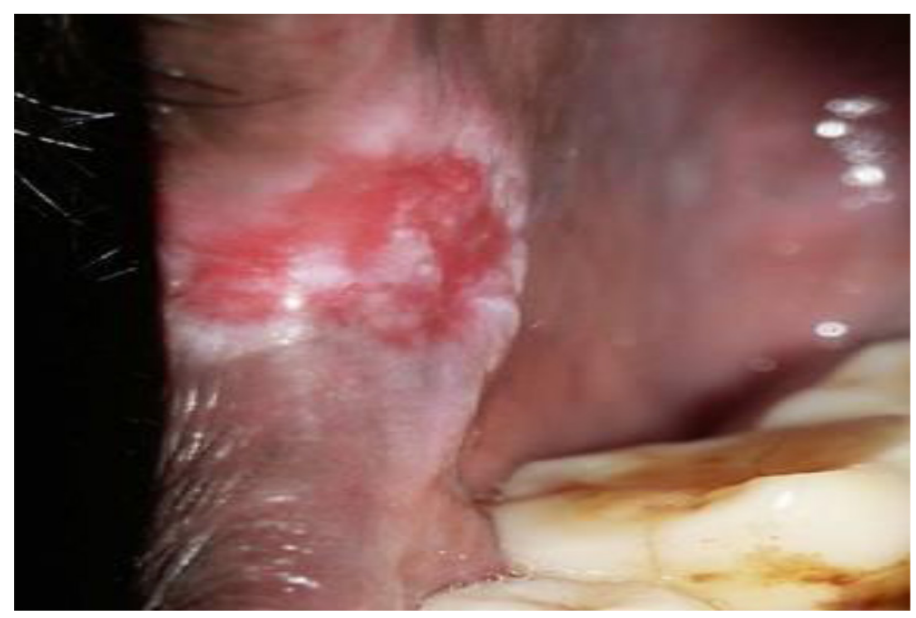

Figure 3: Red patch.

\section{Mass or Lump in the Neck and Neighbouring Regions}

Oral cancer has an abundant potential for metastasis to head and neck lymph nodes with $34 \%$ to $50 \%$ of reported incidence. Metastatic spread

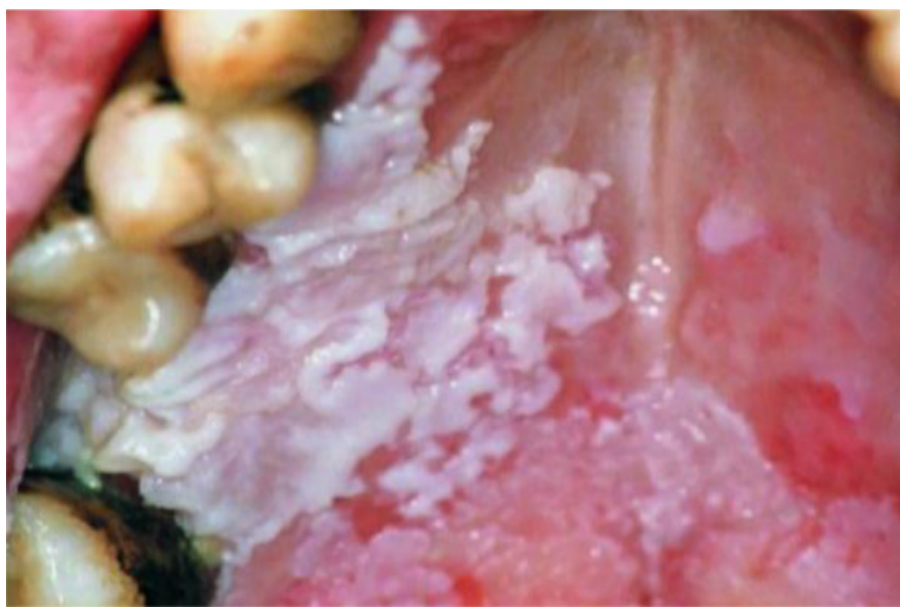

Figure 4: Exophytic growth.

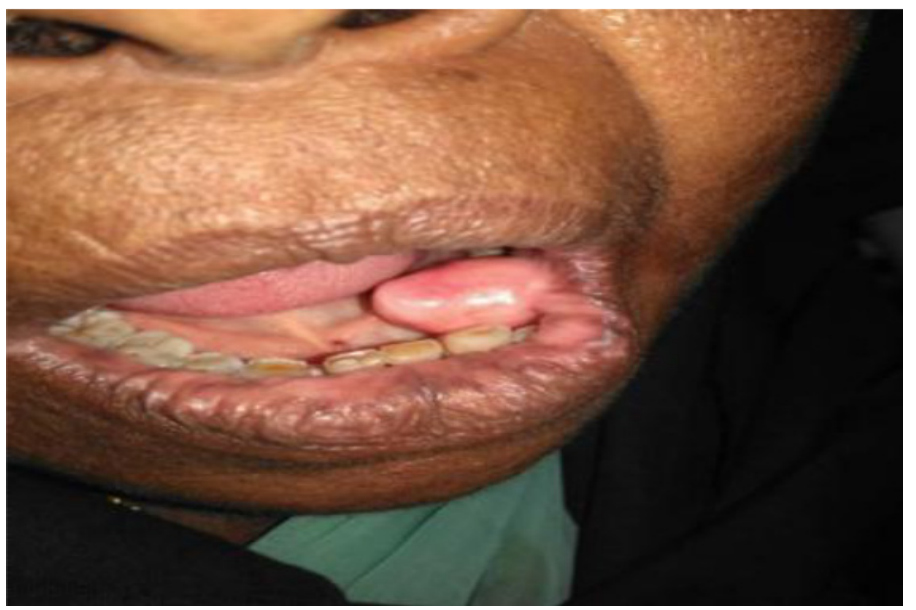

Figure 5: A Mass/lump appearance.

to cervical lymph nodes result in decreased survival rate in Oral Squamous Cell Carcinoma (OSCC) patients. Lymphedema is a common late effect in patients with head and neck cancer, and it develops either as a secondary deposit or metatatic spread via multiple external and internal anatomical locations. Oral malignancies associated with neck mass includes Squamous cell carcinoma, ${ }^{29-32}$ Metastatic tumors, ${ }^{33,35}$ Melanomas, ${ }^{22}$ Lymphomas $^{34}$ and Salivary gland neoplasms. ${ }^{6}$

\section{Mobility /Displacement/Non Vital Teeth/Peri Implantitis}

Primary squamous cell carcinoma which occurs in the gingival region frequently gives these types of tooth related clinical features as an early sign. These are mainly due to involvement of periodontium with cancerous lesion. ${ }^{36,37}$ However, tooth mobility, displacement and nonvital teeth are most common signs present in central tumors of the jaws. ${ }^{23,24}$ They include Malignant odontogenic tumors, ${ }^{24,38}$ Osteosarcomas, ${ }^{40}$ Ewings sarcoma, ${ }^{41}$ Intraosseous muco epidermoid carcinomas, ${ }^{42}$ Burkitts lymphoma ${ }^{43}$ Multiple myelomas. ${ }^{28}$ Primary malignancies such as Squamous cell carcinoma and Large B cell lymphoma may also clinically present as peri implantitis. ${ }^{44}$

\section{Tooth Pain and Referral Pain}

Orofacial pain may be a presenting symptom of primary tumors, metastatic disease, or distant non-metastasized cancer. Mechanisms under- 
lying cancer-associated pain are very complex. ${ }^{45}$ Oral squamous cell carcinoma could also present as tooth pain as a symptom. The histological endophytic growth patterns of OSCC might be significant risk factors for the presence of spontaneous pain before treatment resulting in poor prognosis. ${ }^{46,47}$ Sound painful tooth/teeth were the most common symptom in OSCC patients $(27.5 \%)^{47}$ and the initial clinical presentation could be a tooth pain. ${ }^{48}$ Most frequent initial symptom was toothache $(36.2 \%)$ in malignant neoplasm of maxillary antrum. ${ }^{49}$ Radiating ear pain in lymphoma of the tongue is also reported..$^{50}$ Tumors presented with tooth pain includes Squamous cell carcinomas, ${ }^{46,47,48}$ Malignant tumors of the jaw commonly osteosarcoma, ${ }^{24,40}$ Metastatic malignancies, ${ }^{25}$ Tumors of maxillary antrum, ${ }^{49}$ Burkitts lymphoma, ${ }^{43}$ Salaivary gland tumors, ${ }^{51}$ Multiple myeloma, ${ }^{52}$ and Malignant melanomas. ${ }^{53}$

\section{Haemorrage - Oral Cavity}

Spontaneous bleeding from mouth is a common symptom in several oral malignancies. Often, it is observed in tongue and gingival region of the mouth.It could be due to primary cancer or secondary to trauma to the malignant lesion.Malignancies commonly presenting with this symptom are Squamous cell carcinoma, ${ }^{3}$ Leukemias, ${ }^{9}$ Malignant melanomas, ${ }^{53}$ Multiple myeloma,${ }^{54}$ Lymphoma, ${ }^{55}$ Sarcoma,${ }^{56}$ Muco epidermoid carcinoma, ${ }^{57}$ and Metastatic tumors. ${ }^{58}$

\section{CONCLUSION}

Health care practitioners should remain alert for signs and symptoms of oral malignant and premalignant lesions while performing routine examinations. Recent studies showed alterations in the incidence of oral cancer regarding to age,gender, etiological factors and the anatomical areas of occurence.These factors insisted the significance of prompt clinical evaluation while examining suspicious oral lesions.Awareness regarding the early signs and symptoms of malignancies would certainly increase the overall survival rate of the cancer patients. In addition, informed discussions regarding warning signs and symptoms could be beneficial while 'observe and treat' cases of high risk potentially malignant disorders. It is mandatory for the physician to re-evaluate and perform gold standard biopsy procedure that would aid in appropriate diagnosis and facilitate the treatment with better prognosis in suspicious lesions. Biopsy might also avoid either over diagnosis nor over treatments. In oral cancer patients, evaluations of the other potential areas like esophagus,larynx, hypopharynx, and lungs should be accomplished in addition to the routine clinical and laboratory investigations to rule out another primary cancers. Though biopsy is considered as confirmatory diagnosis it is emphasized to validate and expanding the utility of auxillary advanced diagnostic procedures clinically to identify early cancerous lesions.

Physicians decision would depend on further advanced diagnostic procedures or specialist referral without any additional delay. This article has focused primarily to shed light on the "Warning signs and symptoms" - oral cancer" as a tool for alerting clinicians for early diagnosis, effective treatment and better prognosis of patient.

"Caution, Care and Attention - Basic tool in eradication of oral cancer".

\section{CONFLICTS OF INTEREST}

The authors declare no conflict of interest.

\section{ACKNOWLEDGEMENT}

We wanted to acknowledge Dr.Sathya Kannan BDS MDS MFDS RCS(EDIN) for her support in bringing out this article.

\section{ABBREVIATIONS}

OSCC: Oral squamous cell carcinoma.

\section{REFERENCES}

1. Scully C, Porter S . Orofacial disease: update for the dental clinical team: 2. Ulcers, erosions and other causes of sore mouth. Part I. Dent Update. 1998;25(10):478-84.

2. Huber MA. A review of premalignant oral conditions. Tex Dent J. 2006;123(6):502-9.

3. Yang SW, Lee YS, Chang LC, Hwang CC, Chen TA. Use of endoscopy with narrow-band imaging system in detecting squamous cell carcinoma in oral chronic non-healing ulcers. Clin Oral Investig. 2014;18(3):949-59.

4. Sharma RG, Bang B, Verma H, Mehta JM. Profile of oral squamous cell cancer in a tertiary level medical college hospital: a $10 \mathrm{yr}$ study. Indian J Surg Oncol. 2012;3(3):250-4

5. Zhao C, Liu JZ, Wang SB, Wang SC .Adenoid cystic carcinoma in the maxillary gingiva: a case report and immunohistochemical study. Cancer Biol Med. 2013;10(1):52-4.

6. Herd MK, Murugaraj V, Ghataura SS, Brennan PA, Anand R 2012.Low-grade mucoepidermoid carcinoma of the palate-a previously unreported case of metastasis to the liver. J Oral Maxillofac Surg. 2012;70(10):2343-6.

7. Hirota J, Osaki T, Yoneda K, Yamamoto T, Ueta E, Hiroi M, et al. Midline malignant B-cell Lymphoma with leukemic transformation. Cancer. 1992;70(12):2958-62.

8. Nikolaos N, Gigorios P, Konstantinos k, Savvas T, Vassiliki Z, Alexandra S, et al. Extranodal nasal-type NK/T- cell lymphoma of palate and paranasal sinuses. A J Case Rep. 2012;13:79-85.

9. Hou GL, Huang JS, Tsai CC . Analysisof oral manifestations of leukemia: a retrospective study. Oral Dis. 1997;3(1):31-8.

10. Dean AK, Ferguson JW, Marvan ES. Acute leukaemia presenting as oral ulceration to a dental emergency service. Aust Dent J. 2003;48(3):195-7.

11. Woods TR, Cohen DM, Islam MA,Kratochvi FJ,Reder SL, Bhattacharyya I. Intraoral basal cell carcinoma, a rare neoplasm: report of three new cases with literature review. Head Neck Pathol. 2014;8(3):339-48.

12. Born S, Gaber G, Willgeroth K, Wagner U, Haneke E, Marsch WC 1999. Metastasising malignant lymphoma mimicking necrotising and hyperplastic gingivostomatitis. Eur J Dermatol. 1999;9(7):569-73.

13. Hirshberg A, Shnaiderman-Shapiro A, Kaplan I, Berger R. Metastatic tumours to the oral cavity-Pathogenesis and analysis of 673 cases.Oral Oncology 2008;44(8):743-52.

14. Payne TF. Why are white lesions white? Oral Surg. 1975;40(5):652-8.

15. Ding Y, Ma L, Shi L, Feng J, Liu W, Zhou Z . Papillary squamous cell carcinoma of the oral mucosa: a clinicopathologic and immunohistochemical study of 12 cases and literature review. Ann Diagn Pathol. 2013;17(1):18-21.

16. Van Gestel KM, Buurman DJ, Pijls R, Kessler PA, Van den Ende PL, Hoffmann AL, et al. Locally advanced verrucous carcinoma of the oral cavity: Treatment using customized mold HDR brachytherapy instead of hemi-maxillectomy. Strahlenther Onkol. 2013;189(10):894-8.

17. Reichart PA, Philipsen HP. Oral erythroplakia-a review. Oral Oncol. 2005;41(6):551-61.

18. Scuibba JJ. Oral cancer. The importance of early diagnosis and treatment. Am J Clin Dermatol. 2001;2(4):239-51.

19. Yu DX, Pi SJ, Zhang WS. Clinical manifestation of Kaposi sarcoma in otorhinolaryngology head and neck surgery. Zhonghua Er Bi Yan Hou Tou Jing Wai Ke Za Zhi. 2013;48(3):241-3.

20. Kruse AL, Grätz KW, Obwegeser JA, Lübbers HT. Malignant minor salivary gland tumors: a retrospective study of 27 cases. Oral and Maxillofacial Surgery. 2010;14(4):203-9.

21. Lee SS, Kim HK, Choi SC, Lee JI. Granulocytic sarcoma occurring in the maxillary gingiva demonstrated by magnetic resonance imaging. Oral Surg Oral Med Oral PatholOral Radiol Endod. 2001;92(6):689-93.

22. Pai A, Prasad S, Patil BA, Dyasanoor S, Hedge S. Oralpigmentation: case report and review of malignant melanoma with flow charts for diagnosis and treatment. Gen Dent. 2012;60(5):410-6

23. Bavitz JB, Patterson DW, Sorensen S. Non-Hodgkin's lymphoma disguised as odontogenic pain. J Am Dent Assoc. 1992;123(3):99-100.

24. Coleman H, Sukumar S. Malignant tumours of the jaws. SADJ. 2012;67(10):578-80.

25. Hirshberg A, Shnaiderman-Shapiro A, Kaplan I, Berger R. Metastatic tumours to the oral cavity - Pathogenesis and analysis of 673 cases. Oral Oncol. 2008;44(8):743-52.

26. Fitzpatrick SG, Neuman AN, Cohen DM, Bhattacharyya I. Papillary Variant of Squamous Cell Carcinoma Arising on the Gingiva: 61 Cases Reported from Within a Larger Series of Gingival Squamous Cell Carcinoma. Head Neck Pathol. 2013;7(4):320-26.

27. Ponniah I. A rare case of sialadenoma papilliferum with epithelial dysplasia and carcinoma in situ. Oral Surg Oral Med Oral Pathol Oral Radiol Endod. 2007;104(2):e27-9. 
28. Jain $S$, Kaur $H$, Kansal G, Gupta $P$. Multiple myeloma presenting as gingival hyperplasia. J Indian Soc Periodontol. 2013;17(3):391-3.

29. Li Q, Wu D, Liu WW, Li H, Liao WG, Zhang XR, et al. Survival impact of cervical metastasis in squamous cell carcinoma of hard palate.Oral Surg Oral Med Oral Pathol Oral Radiol. 2013:116(1):23-7.

30. Contaldo M, Di Napoli A, Pannone G, Franco R, lonna F, Feola A, et al. Prognostic implications of node metastatic features in OSCC: A retrospective study on 121 neck dissections. Oncol Rep. 2013;30(6):2697-704.

31. Sathyanarayan $V$, Bharani SK. Enlarged lymph nodes in head and neck cancer: Analysis with triplex ultrasonography. Ann Maxillofac Surg. 2013;3(1):35-9.

32. Sumioka S, Sawai NY, Kishino M, Ishihama K, Minami M, Okura M. Risk factors for distant metastasis in squamous cell carcinoma of the oral cavity. J Oral Maxillofac Surg. 2013;71(7):1291-97.

33. Gropper AB, Girouard SD, Hojman LP, Huang SJ, Qian X, Murphy GF, et al. Metastatic basal cell carcinoma of the posterior neck: case report and review of the literature. J Cutan Pathol. 2012;39(5):526-34

34. Bechir A, Asma A, Haifa R, Nesrim A, Yosra BY. Badreddine S, et al. Primary Bcell lymphoma of the tongue base: a case report. Pan Afr Med J. 2016;25:174.

35. Huang $\mathrm{CH}$, Chang $\mathrm{YL}$, Yang MC, Hsueh $\mathrm{C}$, Yu CT. Lung cancer metastatic to the maxillary gingiva-a case report and literature Review. 2005;41(6):118-20.

36. Khan SM, Gossweiler MK, Zunt SL, Edwards MD, Blanchard SB. Papillary squamous cell carcinoma presenting on gingiva. J periodontal. 2005;76(12):2316-21.

37. Kim OS, Uhm SW, Kim SC, Lee BA, Kim OJ, Kim YJ et al. A case of squamous cell carcinoma presenting as localized severe periodontitis in the maxillary gingiva. J periodontal. 2012;83(6):753-6.

38. Richardson MS, Muller. Malignant odontogenic tumors: an update on selected tumors. Head Neck Pathol. 2014;8(4):411-20.

39. Nomura T, Monobe H, Tamaruya N, Kishishita S, Saito K, Miyamoto R, et al. Primary intraosseous squamous cell carcinoma of the jaw: two new cases and review of the literature. Eur Arch Otorhinolaryngol. 2013;270(1):375-9.

40. Khammissa RA, Mabusela M, Wood NH, Bouckaert M, Meyerov R, Lemmer J, et al . Osteosarcoma of the jaw. A brief review and a case report. SADJ. 2009;64(5):220-1.

41. De Santos LA, Jing BS. Radiographic findings of Ewing's sarcoma of the jaws. Br J Radiol. 1978;51(609):682-7.

42. Chan KC, Pharoah M, Lee L, Weinreb I, Perez-Ordonez B. Intraosseous mucoepidermoid carcinoma: a review of the diagnostic imaging features of four jaw cases. Dentomaxillofac Radiol. 2013;42(4):20110162.

43. Omoregie FO, Saheeb BD, Onasanya PO . Periradicular burkitt's lymphoma: a report of 2 cases from Nigeria and review of the literature. Afr J Med Med Sci.
2008;7(3):279-83.

44. Raiser V, Abu-El Naaz, Shlomi B, Fliss DM, Kalpan I. Primary Oral Malignancy imitating Peri-Implantitis. J Oral Maxillofac Surg. 2016;74(7):1383-90.

45. Fischer DJ, Klasser GD, Epstein JB . Cancer and orofacial pain. Oral Maxillofac Surg Clin North Am. 2008;20(2):287-301.

46. Sato J, Yamazaki Y, Satoh A, Onodera-Kyan M, Abe T, Satoh T, et al. Pain may predict poor prognosis in patients with oral squamous cell carcinoma. Oral Surg Oral Med Oral Pathol Oral Radiol Endod. 2011;111(5):587-92.

47. Adeyemi BF, Kolude B . Clinicalpresentation of oralsquamous cell carcinoma. Niger Postgrad Med J. 2013;20(2):108-10.

48. T Singh, M Schenberg. Delayed diagnosis of oral squamous cell carcinoma following dental treatment. Ann R Col Surg Engl. 2013;95(5):369-73.

49. Stavrianos SD, Camilleri IG, mclean NR, Piggot TA, Kelly CG, Soames JV. Malignant tumours of the maxillary complex: an 18-year review. Br J Plast Surg. 1998;51(8):584-8.

50. MJ Veness. Tongue cancer in younger patients. Australas Radiol. 1999;43(1):76-81.

51. Nagarkar NM, Bansal S, Dass A, Singhal SK, Mohan H. Salivary gland tumors - our experience. Indian J Otolaryngol Head Neck Surg. 2004;56(1):31-4

52. Pinto LS, Campagnoli EB, Leon JE, Lopes MA, Jorge J. Maxillary lesion presenting as a first sign of multiple myeloma: case report. Med Oral Patol Oral Cir Bucal. 2007;12(5):E344-7.

53. Mccaffrey TV, Neel HB, Gaffey TA. Malignant melanoma of the oral cavity: review of 10 cases. Laryngoscope. 1980;90(8):1329-35.

54. Mozaffari E, Mupparapu M, Otis L. Undiagnosed multiple myeloma causing extensive dental bleeding: report of a case and review. Oral Surg Oral Med Oral Pathol Oral Radiol Endod. 2002;94(4):448-53.

55. Inchingolo F, Tatullo M, Abenavoli FM, Marrelli M, Inchingolo AD, Inchingolo AM et al. Non-Hodgkin lymphoma affecting the tongue: unusual intra-oral location. Head Neck Oncol. 2011;3:1.

56. Fanburg-Smith JC, Furlong MA, Childers EL.Oral and salivary gland angiosar coma: a clinicopathologic study of 29 cases.Mod Pathol. 2003;16(3):263-71.

57. Leong SC, Pinder E, Sasae R, Mortimore S. Mucoepidermoid carcinoma of the tongue.Singapore Med J. 2007;48(10):e272-4.

58. Inaba H, Kanazawa N, Wada I, Yoneyama K, Fujii T, Hoshino T, et al. A case of hepatocellular carcinoma with bleeding gingival metastasis treated by transcatheter arterial embolization. Nihon Shokakibyo Gakkai Zasshi =Japanese journal of gasteroenterology. 2011;108(1):95-102.

Article History: Submission Date : 11-01-2018 ; Revised Date : 10-02-2018; Acceptance Date : 17-02-2018.

Cite this article: Muthu K, Vedam V, Sivadas G. Warning Signs and Symptoms of Oral Cancer and its Differential Diagnosis. J Young Pharm. 2018;10(2):138-43. 